\title{
Larval Sea Lampreys (Petromyzon marinus) Do Not Emigrate from a Risky Habitat Under Semi-natural Conditions
}

\author{
JACQUELINE L. AyotTE ${ }^{1}$ and ISTVÁN IMrE ${ }^{1,2}$ \\ ${ }^{1}$ Department of Biology, Algoma University, 1520 Queen St. East, Sault Ste. Marie, Ontario P6A 2G4 Canada \\ ${ }^{2}$ Corresponding author: istvan.imre@algomau.ca
}

Ayotte, Jacqueline L., and István Imre. 2016. Larval Sea Lampreys (Petromyzon marinus) do not emigrate from a risky habitat under semi-natural conditions. Canadian Field-Naturalist 130(1): 49-52.

Sea Lamprey (Petromyzon marinus), invaded the upper Great Lakes in the early $20^{\text {th }}$ century, precipitating abrupt declines in a number of native fish species. A recently proposed alternative method for the behavioural manipulation of Sea Lamprey populations is the use of conspecific damage-released alarm and predator cues as potential repellents. We examined whether larval Sea Lamprey (Petromyzon marinus) ammocoetes can be manipulated to emigrate from an area by labeling their habitat "risky" with the regular release of chemosensory alarm cues over several days. In a semi-natural laboratory environment, we exposed eight replicate groups of eight ammocoetes twice a day, for 7 days, to deionized water (control), ammocoete whole-body extract (damage-released alarm cue), and 2-phenylethylamine $\mathrm{HCl}$ (predator cue). None of the experimental stimuli induced emigration from the experimental arena. This approach does not hold any promise for ammocoete behavioural manipulation in the context of a Sea Lamprey integrated management program.

Key Words: Sea Lamprey; Petromyzon marinus; ammocoete; repellent; chemosensory cues; risk avoidance

\section{Introduction}

Methods to control Sea Lamprey (Petromyzon marinus) populations include the use of the larval lampricide, 3-trifluoromethyl-4-nitrophenol, low-head barrier dams, and trapping (McLaughlin et al. 2007). To reduce the reliance on lampricides as a management tool, the Great Lakes Fishery Commission encouraged the development of alternative methods for Sea Lamprey population control (GLFC 2011). A recently proposed alternative method is the use of conspecific damage-released alarm and predator cues as potential repellents (Imre et al. 2010).

As many aquatic organisms use chemosensory cues (Kats and Dill 1998) to assess relevant threats, a natural repellent-based approach could contribute effectively to the integrated Sea Lamprey population control program. A push-pull strategy for Sea Lamprey control has been recently suggested by Imre et al. (2010), in which sex pheromones combined with chemosensory alarm cues would function to manipulate the behaviour of migratory Sea Lampreys by pushing them away from spawning habitats and luring them into areas where traps or other forms of control are deployed. Recent studies have demonstrated that migratory Sea Lampreys strongly avoid conspecific damage-released alarm and predator cues (Di Rocco et al. 2014; Imre et al. 2014).

There is little information available about the response of ammocoetes to chemosensory alarm cues. Ammocoetes create U-shaped burrows in sandy substrates in which they may spend over a decade as filter feeders (Potter 1980). Recently, Perrault et al. (2014) found that free-swimming ammocoetes exposed to conspecific damage-released alarm cues increased their number of escape attempts and directional changes.
However, the findings of Perrault et al. (2014) are difficult to extrapolate to natural systems, because the study did not provide burrowing substrate for the ammocoetes.

The objective of this study was to determine whether ammocoetes can be manipulated to leave established burrows if their habitat becomes "risky." Consistent with the findings of Kim et al. (2011), we expected that the ammocoetes would emigrate from experimental arenas that were regularly exposed to chemosensory alarm cues. Further, we predicted that emigration would occur at night. These predictions were tested in stream channels supplied with natural substrate and water from the St. Marys River in Sault Ste. Marie, Ontario, Canada.

\section{Methods}

\section{Experimental subjects}

Ammocoetes were collected by Fisheries and Oceans Canada in September 2014 by electrofishing in Crystal Creek (Sault Ste. Marie). They were kept under a natural photoperiod ( $11 \mathrm{~h}$ light, $13 \mathrm{~h}$ dark) in stream channels at Fisheries and Oceans Canada Sea Lamprey Control Centre, Sault Ste. Marie, with a 5-cm sand substrate to allow for burrowing. The stream channels were supplied with unfiltered water at ambient water temperature (mean \pm standard deviation $=9 \pm 0.5^{\circ} \mathrm{C}$ ) pumped directly from the St. Marys River at a constant rate of $0.15 \mathrm{~L} / \mathrm{s}$.

\section{Stimulus preparation}

An ammocoete whole-body extract was prepared using five ammocoetes of unknown sex (mean weight $=4.1 \pm 1.4 \mathrm{~g}$ ). Ammocoetes were euthanized with a swift blow to the head (use of tissue donor and experimental subjects were approved by the Algoma Uni- 
versity Animal Care Committee; AUP no. 2014-II-02). We harvested $20.5 \mathrm{~g}$ of body tissue from donors and homogenized it in $50 \mathrm{~mL}$ of distilled water. We filtered the extract through cheesecloth and diluted it to a final volume of $500 \mathrm{~mL}$. We further diluted the solution to one part alarm cue to 10 parts water and froze it in 10$\mathrm{mL}$ aliquots at $-20^{\circ} \mathrm{C}$. We also prepared $10 \mathrm{~mL}$ of 0.32 M 2-phenylethylamine $\mathrm{HCl}$ (PEA $\mathrm{HCl}$ ) solution just before distribution into experimental arenas. PEA HCl is a compound present in mammalian urine that induces an avoidance response in migratory Sea Lampreys (Imre et al. 2014).

Assuming full and uniform distribution of these stimuli in the experimental arena from top to bottom, the minimum concentration experienced by the ammocoetes was about $71 \mathrm{ppm}$ for the alarm cue and $2.3 \times$ $10^{-4} \mathrm{M}$ for the PEA HCl. The concentration of these stimuli was considerably higher than that needed to induce significant avoidance responses by migratory Sea Lampreys (3.3 ppm for the Sea Lamprey extract and $2.1 \times 10^{-5} \mathrm{M}$ for PEA HCl; Imre et al. 2014).

\section{Experimental set-up}

Six stream channels at the Fisheries and Oceans Canada Sea Lamprey Control Centre were used to create 12 experimental arenas (two parallel experimental arenas per stream channel). The two experimental arenas ( $20 \mathrm{~cm}$ wide by $90 \mathrm{~cm}$ long) and associated emigration areas $(20 \mathrm{~cm}$ wide by $30 \mathrm{~cm}$ long) in each stream channel were separated by pine boards $(2.5 \mathrm{~cm}$ wide by $15 \mathrm{~cm}$ high by $120 \mathrm{~cm}$ long) positioned in the middle of each channel and delimited by perforated metal barriers at the upstream end and metal mosquito nets inserted at $90 \mathrm{~cm}$ and $120 \mathrm{~cm}$, respectively, from the upstream end (Figure 1). Experimental animals could enter the emigration area through a slit $(1 \mathrm{~cm}$ above the substrate) cut in the mosquito net separating the emigration area from the experimental arena.

The upstream end of the experimental arenas was located $60 \mathrm{~cm}$ downstream from the inflow. We added fine sand (to a depth of approximately $5 \mathrm{~cm}$ ) to each experimental arena so that ammocoetes could establish burrows. The discharge in each stream channel was adjusted to $0.15 \mathrm{~L} / \mathrm{s}$ to create a water velocity of about $0.01 \mathrm{~m} / \mathrm{s}$ in the experimental arenas. Dye tests were performed to determine the water velocity and the optimal location for administering the stimuli. In these tests, the dye spread quickly to cover the whole surface of the experimental arenas and blanketed the substrate uniformly.

\section{Experimental design}

The experiment was performed between 12 and 25 October 2014 at the Fisheries and Oceans Canada Sea Lamprey Control Centre. Eight randomly chosen ammocoetes were transferred to each of the experimental arenas. After a 24-h acclimation period, each of the replicate arenas was injected with one of three treatments twice a day, for 7 days: distilled water (control), ammocoete whole-body extract, or PEA HCl. For each treatment, we performed eight replicates.

Each morning at 0900 and in the evening at sundown, $10 \mathrm{~mL}$ of one of the three stimuli were injected $10 \mathrm{~cm}$ upstream from the upper end of each experimental arena. The stimulus injection areas of the two parallel experimental arenas in the same stream channel were separated by a $40 \mathrm{~cm}$ long wooden barrier to prevent mixing of the administered stimuli. Stimuli of the same type were injected upstream of both experimental arenas in the same stream channel. Stimuli were administered in a single dose to mimic a single predation event (ammocoete whole-body extract) or the presence of a mammalian predator (PEA HCl). Treatments were rotated among the six stream channels to eliminate any potential biases created by their position.

We recorded the number of ammocoetes in the emigration areas in the morning (result of emigration at night) and at sundown (result of emigration during the day). The ammocoetes were in the experimental arenas for 7 days or, if any individuals left the experimental arena earlier, they were removed, quickly euthanized using tricaine methanesulfonate $(0.015 \mathrm{~mL} / \mathrm{L})$, weighed

\begin{tabular}{|c|c|c|c|}
\hline & $\begin{array}{c}\text { Emigration } \\
\text { area }\end{array}$ & Experimental arena \\
\hline & $\begin{array}{c}\text { Emigration } \\
\text { area }\end{array}$ & Experimental arena & $\mathrm{x}$ \\
\hline
\end{tabular}

FIGURE 1. Overhead view of a stream channel containing two parallel experimental arenas with their associated emigration areas used to test the response of Sea Lamprey (Petromyzon marinus) ammocoetes to conspecific damage-released alarm cues and a predator cue under semi-natural conditions. The arrow indicates the direction of water flow. The experimental stimuli were released in the locations indicated with an $\mathrm{x}$ in the diagram. The barrier separated the stimulus release areas to avoid mixing of the stimuli destined for the individual experimental arenas. 
(to the nearest $0.1 \mathrm{~g}$ ), and measured for total length (to the nearest $\mathrm{mm}$ ).

A total of 192 ammocoetes were used in the experiment (mean total length $=8.0 \pm 1.9 \mathrm{~cm}$, mean wet mass $=1.1 \pm 0.6 \mathrm{~g})$. Water temperature (mean $=9 \pm$ $\left.0.5^{\circ} \mathrm{C}\right)$, discharge $($ mean $=0.14 \pm 0.01 \mathrm{~L} / \mathrm{s})$, water velocity (mean $=0.01 \pm 0.003 \mathrm{~m} / \mathrm{s}$ ), and water depth (mean $=7.6 \pm 0.2 \mathrm{~cm})$ were recorded throughout the experiment.

\section{Statistical analysis}

One-way analyses of variance (ANOVA) were used to compare the number of emigrants, wet mass, total length, water velocity, discharge, and water depth among treatments. All statistical analyses were performed using Statistica 12 (StatSoft Inc., Tulsa, Oklahoma, USA) with a significance level of $\alpha=0.05$.

\section{Results}

Overall, no ammocoetes emigrated from the experimental arenas. There were no statistical differences in wet mass or total length between the treatment groups $\left(F_{2,189}=1.65, P=0.19 ; F_{2,189}=1.85, P=0.16\right.$, respectively). Similarly, water discharge and velocity were not significantly different between treatments $\left(F_{3,12}=1.56, P=0.25 ; F_{3,12}=2.05, P=0.16\right.$, respectively), but water depth was $\left(F_{3,4}=18.87, P<0.01\right)$.

\section{Discussion}

This is the first study to investigate the willingness of ammocoetes to emigrate from a risky habitat in a semi-natural environment. We predicted that ammocoetes periodically exposed to conspecific whole-body extract and predator cues over several days would emigrate at night in search of a more suitable habitat. Contrary to our predictions, no ammocoetes left the risky experimental arenas over 7 days of repeated exposure. In contrast, juvenile Atlantic Salmon (Salmo salar) density significantly decreased in stream areas labeled daily with damage-released alarm cues (Kim et al. 2011), compared with control sections.

We noted only one variance in ammocoete behavior during the experiment; during the evening application of the stimuli, one ammocoete was noted slowly swimming upstream while $\mathrm{PEA} \mathrm{HCl}$ was administered. When the ammocoete arrived at the front end of the experimental arena and was exposed to PEA $\mathrm{HCl}$, it rapidly changed direction, swimming quickly to the opposite end of the arena and vigorously burrowing into the substrate. This behaviour suggests that ammocoetes do respond to PEA $\mathrm{HCl}$, not unlike migratory Sea Lampreys (Imre et al. 2014; Di Rocco et al. 2014), but the alarm cues in our experiment did not seem sufficient to initiate relocation once ammocoetes were established in burrows. Vulnerability to predation at this stage in life apparently prevented the ammocoetes from leaving the safety of an established burrow.

Habitat choice is crucial for survival and maximizing individual fitness. Typically, animals will choose a habitat that is plentiful in food and low in predators, but trade-offs often create more risky situations (Lima and Dill 1990). Although it would seem evolutionarily unfavourable to occupy a habitat where there is a high risk of predation, it is apparently beneficial for the ammocoetes to remain in the safety of their burrows if danger is detected nearby, rather than risk being eaten while trying to emigrate.

Quintella et al. (2005) found that ammocoetes occupying favourable environments may remain in their burrows for several months without moving. The favourable habitat provided by our experimental set-up - low ammocoete density, optimal substrate composition, and consistent environmental conditions - could partly explain why we did not observe any emigrating ammocoetes. Thus, our findings might not reflect an accurate representation of ammocoete behavioural responses at other times of the year, as most ammocoete movement occurs during spring flooding (Manion and McLain 1971). Future research should examine the effect of repellents on ammocoetes in the spring. Alternatively, it is possible that a higher concentration or more frequent addition of the stimuli is needed to induce ammocoete emigration from the experimental arenas.

In conclusion, no ammocoetes left the experimental area in the repeated presence of damage-released alarm or predator cues throughout the experiment. This approach appears to be ineffective as a natural deterrent for ammocoetes established in burrows.

\section{Acknowledgements}

Funding for this project was provided by the Great Lakes Fishery Commission and Northern Ontario Heritage Fund Corporation. We are grateful to Fisheries and Oceans Canada for logistical support. This manuscript was improved by constructive comments from C. B. Renaud, S. M. Nowicki, and an anonymous reviewer.

\section{Literature Cited}

Di Rocco, R. T., C. F. Belanger, I. Imre, G. E. Brown, and N. S. Johnson. 2014. Daytime avoidance of chemosensory alarm cues by adult sea lamprey (Petromyzon marinus). Canadian Journal of Fisheries and Aquatic Sciences 71: 824-830.

GLFC (Great Lakes Fishery Commission). 2011. Strategic vision of the Great Lakes Fishery Commission 2011-2020. GLFC, Ann Arbor, Michigan, USA. Accessed 28 October 2014. http://www.glfc.org/pubs/SpecialPubs/StrategicVi sion 2012.pdf.

Imre, I., G. E. Brown, R. A. Bergstedt, and R. McDonald. 2010. Use of chemosensory cues as repellents for sea lamprey: potential directions for population management. Journal of Great Lakes Research 36: 790-793.

Imre, I., R. T. Di Rocco, C. F. Belanger, G. E. Brown, and N. S. Johnson. 2014. The behavioural response of adult Petromyzon marinus to damage-released alarm and predator cues. Journal of Fish Biology 84: 1490-1502. 
Kats, L. B., and L. M. Dill. 1998. The scent of death: chemosensory assessment of predation risk by prey animals. Ecoscience 5: 361-394.

Kim, J., J. W. A. Grant, and G. E. Brown. 2011. Do juvenile Atlantic salmon (Salmo salar) use chemosensory cues to detect and avoid risky habitats in the wild? Canadian Journal of Fisheries and Aquatic Sciences 68: 655-662.

Lima, S. L., and L. M. Dill. 1990. Behavioural decisions made under the risk of predation: a review and prospectus. Canadian Journal of Zoology 68: 619-640.

Manion, P. J., and A. L. McLain. 1971. Biology of larval sea lampreys (Petromyzon marinus) of the 1960 year class, isolated in the Big Garlic River, Michigan, 1960-1965. Technical report 16. Great Lakes Fishery Commission, Ann Arbor, Michigan, USA.
McLaughlin, R. L., A. Hallett, T. C. Pratt, L. M. O'Connor, and D. G. McDonald. 2007. Research to guide use of barriers, traps, and fishways to control sea lamprey. Journal of Great Lakes Research 33(suppl. 2): 7-19.

Perrault, K., I. Imre, and G. E. Brown. 2014. Behavioural response of larval sea lamprey (Petromyzon marinus) in a laboratory environment to potential damage-released chemical alarm cues. Canadian Journal of Zoology 92: 443-447.

Potter, I. C. 1980. Ecology of larval and metamorphosing lampreys. Canadian Journal of Fisheries and Aquatic Sciences 371641-1657.

Quintella, B. R., N. O. Andrade, R. Espanhol, and P. R. Almeida. 2005. The use of PIT telemetry to study movements of ammocoetes and metamorphosing sea lamprey in river beds. Journal of Fish Biology 66: 97-106.

Received 21 April 2015

Accepted 2 December 2015 